\title{
The Polar Carotenoid Fraction from Sarcina flava
}

\author{
By D. THIRKELL AND M. I. S. HUNTER \\ Department of Biochemistry, Bute Medical Buildings, St. Andrews, Fife
}

(Accepted for publication 28 June 1969)

\begin{abstract}
SUMMARY
The polar carotenoid fraction from Sarcina flava does not not appear to be a free carotenoid, but a carotenoid associated with glucose and a peptide. The glucose seems to be glycosidically bound to the carotenoid through its reducing group. Presumably the peptide is linked to the glucose through either the primary or one of the secondary hydroxyl groups on the carbohydrate molecule. A model of the in vivo state of the carotenoid complex in the bacterial membrane has been proposed.
\end{abstract}

\section{INTRODUCTION}

Thirkell, Strang \& Chapman (1967) examined the carotenoids which could be isolated from Sarcina flava; two of these were shown to be $\mathrm{C}_{50}$ compounds. However, a polar fraction (designated fraction 4) was purified and little positive information was obtained about its constitution. As some of the carotenoids in the membranes of this bacterium are associated with carbohydrate and peptide (Thirkell, Hunter, Crawford \& Fracassini, 1969), the present work was undertaken in an attempt to reveal the nature of this polar material.

\section{METHODS}

Organism. Approximately $3 \mathrm{~kg}$. of deep frozen Sarcina flava (NCTC, 7503) were obtained from Imperial College, London. The organisms had been grown at $37^{\circ}$ in nutrient broth (Oxoid Ltd.) with I \% (w/v) glucose added.

Chemicals. All solvents used were Analar grade and were dried and redistilled before use.

Isolation of the polar carotenoid fraction. This was done by the method previously reported (Thirkell et al. 1967).

Resolution of the polar carotenoid fraction. The total fraction was resolved into four subfractions by thin-layer chromatography on $0.5 \mathrm{~mm}$. layers of silica gel G (Merck) with chloroform + methanol $(90+10, v / v)$ as solvent. The subfractions were again chromatographed to establish their purity and labelled I to 4 in order of decreasing polarity. Since subfractions $I$ and 3 were in approximately equal concentration and constituted about $80 \%$ of the total fraction 4 , all subsequent investigations were done only with these two subfractions.

\section{Tests used for the characterization of the subfractions}

Acetylation. (Kuhn \& Sørensen, 1938; Jensen, 1962). A sample of chromatographically pure material was taken to dryness on a rotary evaporator and then freeze-dried 
for $24 \mathrm{hr}$. The fraction was dissolved in I $\mathrm{ml}$. pyridine, $0 . \mathrm{I}$ to $0.2 \mathrm{ml}$. acetic anhydride added and the reaction allowed to proceed at room temperature in the dark under an atmosphere of nitrogen. Samples were withdrawn every $30 \mathrm{~min}$. for the first $5 \mathrm{hr}$. and then at regular intervals up to $36 \mathrm{hr}$, by which time the reaction was complete. Each sample was examined by thin-layer chromatography with $20 \%(\mathrm{v} / \mathrm{v})$ acetone in light petroleum (b.p. 60 to $80^{\circ}$ ) as solvent. The intermediates were identified visually and after spraying with a saturated solution of antimony trichloride in chloroform (Morton, 1942). Thus the initial compound, the formation of intermediates and the formation of the final ester could be monitored. Spectroscopic examination was used before and after the reaction to test that no degradation had occurred.

Test for tertiary hydroxyl groups after acetylation. (S. L. Jensen, private communication). The esters from above were dried and dissolved in $0.5 \mathrm{ml}$. dry pyridine, $0.2 \mathrm{ml}$. hexamethyldisilane and $0.1 \mathrm{ml}$. trimethylchlorosilane were added and the reaction allowed to proceed at room temperature in the dark and under an atmosphere of nitrogen. After $\mathrm{I} \mathrm{hr}$, carbon tetrachloride was added and the solutions taken to dryness. The products in methanol were examined by thin-layer chromatography as before.

Methylation of carboxyl group. (Metcalfe \& Schmitz, 1961). A sample of the subfractions was dried as for acetylation and dissolved in dry methanol, $0.5 \mathrm{ml}$. methanolic boron trifluoride added and the mixtures refluxed for $3 \mathrm{~min}$. The products were removed into ether and examined chromatographically.

Partition ratio. (Petracek \& Zechmeister, 1956). $95 \%$ (v/v) methanol in water and hexane were equilibrated with each other and the samples dissolved in a small volume of equilibrated methanol. An equal volume of equilibrated hexane was added, and after shaking the two layers were collected. The concentration of pigment in each layer was determined spectrophotometrically.

Spectroscopy. The absorption spectra of the subfractions and their acetates in methanol were determined with a Unicam SP 800 spectrophotometer.

Infra-red spectroscopy. This was done with a Unicam SP $200 \mathrm{G}$ instrument with liquid cells containing solutions in carbon tetrachloride and in carbon disulphide (spectro-quality reagents).

Carbohydrate estimation. The sensitive but general phenol - sulphuric acid method of Whistler \& Wolfrom (1962) was used with solutions of glucose (25 to $100 \mu \mathrm{g} . / \mathrm{ml}$.) as standard.

Identification of carbohydrate. Salton \& Freer (1965) reported that the carbohydrates present in the membranes of the related micro-organisms Sarcina lutea and Micrococcus lysodeikticus were glucose, galactose, mannose and ribose. These sugars were used as standards throughout this part of the work. The subfractions were hydrolysed with $\mathrm{N}-\mathrm{HCl}$ in a sealed tube for $\mathrm{I} 8 \mathrm{hr}$ at $120^{\circ}$ after which the hydrolysates were made acid-free in the normal way. Chromatography was done in a single dimension on Whatman No. I chromatography papers with the following descending solvents: (i) $n$-butanol + pyridine + water $(6+4+3$; by vol.); (ii) $n$-butanol + acetic acid + water $(6+\mathrm{I}+2$; by vol. $)$; (iii) $n$-butanol + acetone + water $(4+5$ $+\mathrm{I}$; by vol.) The standard carbohydrates were run alone and as a mixture, and the hydrolysates were run alone and co-chromatographed with each standard. Since carotenoid in the membranes of Sarcina flava had been shown in some cases to be associated with both carbohydrate and peptide (Thirkell et al. 1969), in all instances, 
duplicate chromatograms were developed, one of which was stained with $0 \cdot 1$ Manisidine phthalate in ethanol (Pridham, 1956) and the other with $2 \%(\mathrm{w} / \mathrm{v})$ ninhydrin in acetone. The former chromatograms were viewed in daylight and under ultraviolet illumination.

Separation of the carbohydrate and peptide by two-dimensional paper chromatography. An attempt was made to separate any free sugar from peptides (or glycopeptides) in the $\mathrm{N}-\mathrm{HCl}$ hydrolysates on Whatman No I chromatography papers with $n$-butanol + acetic acid + water $(6+\mathrm{I}+2$; by vol.) as first solvent and phenol $(400 \mathrm{~g}$. phenol/ I00 ml. water) + water as the second. In each instance, duplicate chromatograms were developed, after removal of the phenol with ether, one was stained with ninhydrin and the other with the anisidine phthalate reagent.

Peptide resolution. Since ninhydrin-positive spots were detected on the above chromatograms and since hydrolysis with $\mathrm{N}-\mathrm{HCl}$ would be more likely to produce small peptides rather than free amino acids, the hydrolysates were resolved by twodimensional thin-layer chromatography on $0.25 \mathrm{~mm}$. layers of silica gel G (Merck) with $n$-butanol + acetic acid + water $(6+2+2$ : by vol.) as first solvent and $n$ propanol + water $(64+36, v / v)$ as second solvent (Randerath, 1964). The plates were stained with ninhydrin.

Amino acid analysis. A sample of each subfraction was taken to dryness and freezedried for $24 \mathrm{hr}$ in a weighed vessel. The weights were determined and the fractions hydrolysed with $6 \mathrm{~N}-\mathrm{HCl}$ in a sealed tube for $\mathrm{I} 8 \mathrm{hr}$ at $120^{\circ}$. The hydrolysates were made acid-free, and then in distilled water they were applied to a Technicon autoanalyser, with norleucine as internal standard.

Estimation of carotenoid. This was estimated spectrophotometrically using a theoretical extinction coefficient of 3000 based on the similarity of the chromophore to that of neurosporene or $\epsilon$-carotene. Such an estimation assumes that the absorption characteristics of the free and bound carotenoid are similar.

\section{RESULTS}

The results for part of the chemical analysis of the subfractions are shown in Table I. For the tests shown in the table, the results from the two subfractions were identical.

\section{Chromatography}

Identification of carbohydrate. The $\mathrm{N}-\mathrm{HCl}$ hydrolysates were resolved into four spots which stained with anisidine phthalate reagent. That with the highest $\boldsymbol{R}_{\boldsymbol{F}}$ value co-chromatographed with glucose, the others did not co-chromatograph with any standard used. However, duplicate chromatograms stained with ninhydrin showed eight spots, four of which had the same $R_{\boldsymbol{F}}$ values as the carbohydrate spots when the chromatograms were run in a single dimension.

Separation of carbohydrate from peptide (glycopeptide). Two-dimensional paper chromatography showed that the carbohydrate spot which co-chromatographed with glucose was a free sugar. The other spots which stained with anisidine phthalate were associated with peptide. Ninhydrin-staining material was also detected which did not appear to be associated with sugar.

Resolution of peptides. Two-dimensional thin-layer chromatography showed that the peptides present in the two hydrolysates were not identical. Calculation of $R_{F}$ 
values showed that most, if not all, of the spots were peptides rather than free amino acids.

Link of carotenoid to glucose. The anisidine phthalate reagent stains with reducing groups only, and the subfractions before hydrolysis did not take up the stain.

Table I. Sarcina flava. Some analytical results obtained from the pigment subfractions 4 ( $i$ ) and 4 (iii)

Test

Acetylation

Tertiary hydroxyl Negative

group

Methylation of Positive carboxyl group

Partition ratio

Spectra

Infrared No cis peak

Result

Positive

$100 \%$ in methanol

$\max .^{-415,437,467}$

$\mathrm{m} \mu$ with original and

final acetate

spectroscopy

\section{Comment}

At least 6 hydroxyl groups (primary or secondary) were acetylated. After acetylation, both subfractions were still polar, suggesting the presence of polar groups other than hydroxyl in the subfractions

Methylation of carboxyl groups on dicarboxylic amino acids

Very polar compound

Chromophore not unduly altered from that shown by free pigments (Thirkell et al. 1967). Association of other molecules with carotenoid does not involve any electrostatic linkages with the electron-dense double bonds of the central conjugated chain.

Carotenoid in all-trans form. The infrared spectrum showed many peaks and proved almost impossible to interpret. This finding might be explained by the presence of carotenoid, carbohydrate and amino acids in the subfractions

Table 2. Sarcina flava. Relative amino acid composition of pigment subfractions 4 ( $i$ ) and 4 (iii) expressed in $\mu M$

$\begin{array}{lcc}\text { Amino acid } & \text { Fraction 4 (i) } & \text { Fraction } 4 \text { (iii) } \\ \text { Aspartic acid } & \mathrm{I} \cdot 3 & 2 \cdot 0 \\ \text { Threonine } & \mathrm{I} \cdot \mathbf{2} & \mathrm{I} \cdot \mathbf{2} \\ \text { Serine } & 3 \cdot 0 & 3 \cdot 0 \\ \text { Glutamic acid } & 3 \cdot 2 & 5 \cdot 0 \\ \text { Glycine } & \mathbf{6} \cdot \mathrm{I} & 7 \cdot \mathrm{I} \\ \text { Alanine } & 2 \cdot \mathrm{I} & 3 \cdot 0 \\ \text { Valine } & \mathrm{I} \cdot 0 & 2 \cdot 0 \\ \text { Isoleucine } & 0 \cdot 8 & \mathrm{I} \cdot 8 \\ \text { Leucine } & \mathrm{I} \cdot 0 & 2 \cdot \mathrm{I} \\ \text { Tyrosine } & 0 \cdot 8 & 1 \cdot 0 \\ \text { Phenylalanine } & 0 \cdot 8 & \mathrm{I} \cdot \mathrm{I} \\ \text { Ornithine } & 1 \cdot 4 & 2 \cdot 8 \\ \text { Lysine } & \mathrm{I} \cdot 0 & 2 \cdot 0 \\ \text { Histidine } & 0 \cdot 9 & \mathrm{I} \cdot \mathrm{I}\end{array}$

Since the hydrolysates in each case did stain, and since the presence of glycopeptides was demonstrated in them, we suggest that the carotenoid is linked glycosidically to the reducing group of glucose. One would expect such a linkage to be split on hydrolysis as reported. 


\section{Amino acid analysis}

The amino acid composition of the two subfractions is shown in Table 2 where the relative amounts of each amino acid are expressed in $\mu \mathrm{M}$.

Constitution of the subfractions by chemical analysis. The relative percentages of carotenoid, glucose and amino acids found were:

$\begin{array}{lccc} & \text { Carotenoid } & \text { Glucose } & \text { Amino acid } \\ \text { Fraction 4 (i) } & 42 & 23 & 24 \\ \text { Fraction 4 (iii) } & 40 & 24^{*} & 27\end{array}$

* This value was checked by using the anthrone method (Scott \& Melvin, 1953).

\section{DISCUSSION}

Both subfractions examined contain carotenoid, glucose and amino acids. The carotenoid is presumed to be the $\mathrm{C}_{50}$ dihydroxy compound (the most polar free carotenoid) isolated by Thirkell et al. (1967) which has become bound to form an integral part of the membrane structure where all of the carotenoid is localized in Sarcina flava (Strang, 1968). The carotenoid seems to be bound to glucose through a glycosidic linkage involving the reducing group of the hexose. The amino acids (peptides) associated with the subfractions must be linked to the hexose in some way involving at least one of the remaining primary or secondary hydroxyl groups of the glucose. If

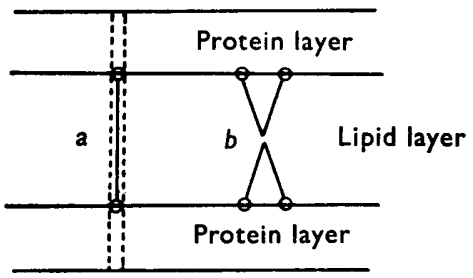

Fig. I.

one considers how this type of complex could be incorporated into the bacterial membrane, let us represent the dihydroxy carotenoid as: $\mathrm{O}-\mathrm{O}$, where $\mathrm{O}=$ hydrophilic hydroxyls and $-=$ hydrophobic central carbon chain. This could fit into the lipid layer of a bimolecular leaflet membrane model as shown in Fig. I. Formation (b) can be excluded since it would require the central double bond to be cis and it is known to be trans. Thus, formation $(a)$ is more likely and the dotted lines would represent the type of material of which these subfractions are constituted. The length of the carotenoid molecule is of the right order to straddle the lipid layer in this way. Figure 2 would represent a more detailed explanation of Fig. I.

If the results presented here are considered in relation to the model, the following observations can be made. (I) The hydroxyl groups acetylated are probably unsubstituted primary or secondary hydroxyls on the glucose molecules. Thus, according to the model, six hydroxyl groups should be available for acetylation and this was demonstrated; (2) the results from amino acid analysis show an amino acid content which in relation to glucose suggests very few amino acid residues attached to each 
glucose molecule. However, during the isolation and purification of these fractions, saponification was used. In the study of glycoprotein structures, $\beta$-elimination is frequently used to verify the existence of O-glycosyl linkages with serine or threonine (Neuberger, Gottschalk \& Marshall, 1966). Although stronger alkali is used for $\beta$-elimination, the conditions used in saponification could well result in the complete loss of amino acids (peptides) from certain glucose molecules if this type of linkage was present. The amino acids with the exception of ornithine (some or all of which may be derived from arginine during saponification) are present in a definite molar ratio, suggestive of a repeating unit of peptide in the protein layer of the membrane. The component amino acids are the same I4 as those found in carotenoid-glycoprotein isolated by using synthetic detergents (Thirkell \& Hunter, 1969). Their relative concentrations differ, suggesting that the lengths of the peptides are not the same. One would expect a longer peptide to be more soluble in an aqueous detergent solvent than in the system used in this work.

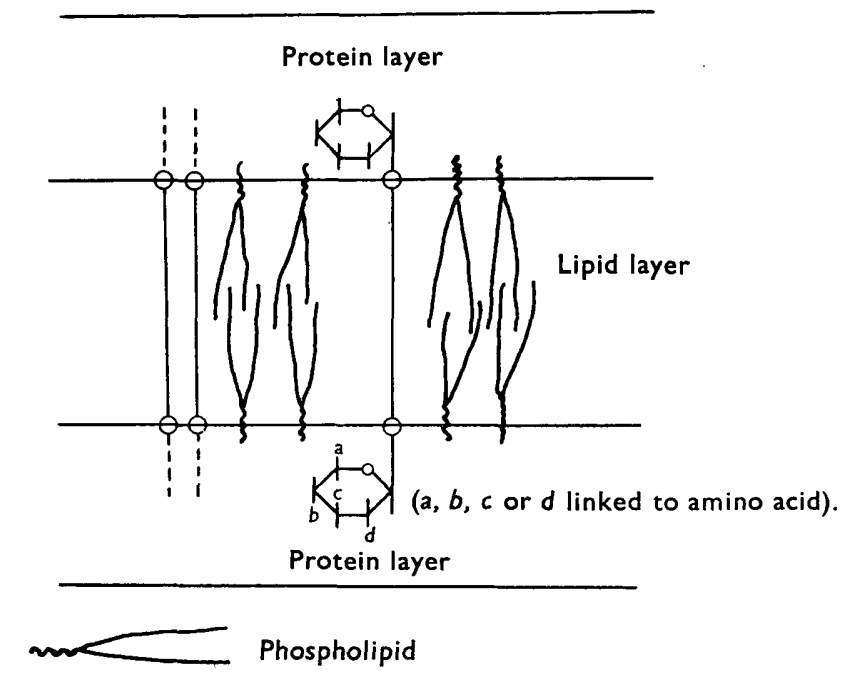

Fig. 2. Proposed model to show incorporation of carotenoid in Sarcina flava membrane.

If there is a repeating unit in the protein layer of the membrane, and if the distance between the carotenoid molecules is less than the length of this repeating unit, then the latter must be fragmented during the isolation of the subfractions. This would release glycocarotenoid to which only part of the unit is bound. Thus, only when a mixture of these fragments is studied should a repeating unit be apparent and be shown by a definite molar ratio of the amino acids present. Such a situation is reported in this work.

We thank Dr A. Serafini-Fracassini for assistance with the amino acid analyses, D. T. is grateful to the Science Research Council for financial support and M. I. S. H. is in receipt of a Science Research Council grant. 


\section{REFERENCES}

JENSEN, S. L. (1962). The constitution of some bacterial carotenoids and their bearing on biosynthetic problems. Ph.D. Thesis, I. Kommisjon Hos, Trondheim: F. Bruns Bokhandel.

KuHN, R. \& Sørensen, N. A. (1938). Uber Astaxanthin und Ovoverdin. Ber. dt. chem. Ges. 7r, 1879.

MetCALFe, L. D. \& SCHMitz, A. A. (I96I). The rapid preparation of fatty acid esters for gas chromatographic analysis. Analyt. Chem. 33, 363.

Morton, R. A. (1942). Absorption Spectra Applied to Vitamins and Hormones. London: A. Hilger.

Neuberger, A., Gotrschalk, A. \& Marshall, R. D. (1966). Glycoproteins. Ed. by A. Gottschalk, p. 273 B.B.A. Library, 5, Amsterdam, London and New York: Elsevier Publishing Co.

Petracek, F. J. \& ZeChMEISTER, L. (1956). Determination of partition coefficients of carotenoids as a tool in pigment analysis. Analyt. Chem. 28, 1484.

Pridham, J. B. (1956). Determination of sugars on paper chromatrograms with p-anisidine hydrochloride. Analyt. Chem. 28, 1967.

RANDERATH, K. (1964). Thin-layer Chromatography. New York and London: Academic Press.

SAlton, M. R. J. \& FreER, J. H. (1965). Composition of the membranes isolated from several Grampositive bacteria. Biochim. biophys. Acta ro7, 531 .

Scott, T. A. \& Melvin, E. H. (1953). Determination of dextran with anthrone. Analyt. Chem. 25, 1656.

Strang, R. H. C. (1968). Some investigations into the Sarcina bacteria. Ph.D. Thesis, St. Andrews University.

Thirkell, D. \& Hunter, M. I. S. (1969). Carotenoid-glycoprotein of Sarcina flava membrane. J. gen. Microbiol. 58, 289.

Thirkell, D., Strang, R. H. C. \& Chalman, J. R. (1967). The pigments of Sarcina flava; a new series of $\mathrm{C}_{50}$ carotenoids. J. gen. Microbiol. 49, 157.

Thirkell, D., Hunter, M. I. S., Crawford, J. \& Fracassini, A. S. (1969). The effect of synthetic detergent on the determination of the molecular weight of a carotenoid-glycoprotein from Sarcina flava. J. gen. Microbiol. 56, I09.

Whistler, R. L. \& Wolfrom, M. L. (1962). Methods in Carbohydrate Chemistry, vol. I, p. 388. New York and London: Academic Press. 